\title{
Olf1/EBF associated zinc finger protein interfered with antinuclear antibody production in patients with systemic lupus erythematosus
}

Xuebing Feng ${ }^{1 *+}$, Rongliang $\mathrm{Li}^{1 \dagger}$, Jing Huang ${ }^{1}$, Huayong Zhang, Lina Zhu' ${ }^{1}$ Bingzhu Hua ${ }^{1}$, Betty P Tsao ${ }^{2}$, Lingyun Sun ${ }^{1 *}$

\begin{abstract}
Introduction: The aim of the study was to determine whether OIf1/EBF associated zinc finger protein (OAZ), a transcription factor encoded by a positional systemic lupus erythematosus (SLE) candidate gene, plays a functional role in the pathogenesis in SLE.
\end{abstract}

Methods: Gene expression levels in peripheral blood cells (PBLS) measured using quantitative real-time polymerase chain reaction (qPCR) were assessed for association with disease activity and the presence of specific autoantibodies. Peripheral blood mononuclear cells (PBMCs) were incubated with specific siRNAs for three days, then cells were harvested for measuring mRNA levels using qPCR, and supernatants for levels of total immunoglobulin (Ig)G and IgM as well as secreted cytokines, chemokine and antinuclear antibodies (ANA) using ELISA. Indirect immunofluorescence was also applied for ANA detection.

Results: OAZ gene expressions in PBLs from 40 ANA-positive SLE patients were significantly increased than those from 30 normal controls $(P<0.0001)$ and 18 patients with rheumatoid arthritis $(P<0.01)$. In SLE patients, OAZ transcripts were positively correlated with SLE disease activity index (SLEDAI) score $(r=0.72, P<0.0001)$ and higher in those positive for anti-dsDNA or anti-Sm antibodies (both $P<0.05$ ). Co-culturing with OAZ siRNAs reduced mRNA levels of OAZ by $74.6 \pm 6.4 \%$ as compared to those co-cultured with non-targeting siRNA and OAZ silencing resulted in reduced total IgG, ANA, interferon (IFN)- $\gamma$, interleukin (IL)-10, IL-12 and IL-21, but elevated CCL2 levels in culture supernatants $(P<0.05)$. The declined ANA levels correlated with inhibited OAZ expression $(r=0.88, P=0.05)$, reduced IL-21 levels $(r=0.99, P<0.01)$, and elevated chemokine (C-C motif) ligand 2 levels $(r=-0.98, P<0.01)$. Expressions of ID1-3 were significantly down-regulated by $68.7 \%, 70.2 \%$ and $67.7 \%$ respectively after OAZ silence, while ID3 was also highly expressed in SLE PBLs $(P<0.0001)$ and associated with disease activity $(r=0.76, P<0.0001)$ as well as anti-dsDNA or anti-Sm antibodies (both $P<0.05)$.

Conclusions: Elevated expression of OAZ transcripts in SLE PBLs were strongly correlated with disease activity. Suppression of OAZ expression inhibited downstream ID levels, and secretion of ANA and IL-21, implicating a role of OAZ pathway in the pathogenesis of SLE.

\footnotetext{
* Correspondence: fengxuebing@hotmail.com; lingyunsun2001@yahoo.com.

cn

† Contributed equally

'Department of Rheumatology, Nanjing Drum Tower Hospital, the Affiliated

Hospital of Nanjing University Medical School, 321 Zhongshan Road,

Nanjing, 210008, PR China
} 


\section{Introduction}

Systemic lupus erythematosus (SLE) is a prototype autoimmune disease with relatively strong genetic components that genome wide linkage scans performed in the past decade have identified chromosome $16 \mathrm{p} 12.3$ to q12.2 to be the second-strongest locus linked to SLE after HLA (6p22.3 to 6p21.1) [1-8]. A positional candidate gene, ITGAM located at 16p11.2, has been recently identified and validated as a lupus susceptibility gene by different groups [9-11]. However, fine mapping experiments of the chromosome 16p locus have shown multiple association signals clustering in several regions $[8,12]$, suggesting more than one gene may be involved in the increased risk of SLE.

We have previously shown overall skewing of the transmission of D16S517 (a microsatellite marker) alleles and preferential transmission of one of its alleles from heterozygous parents to offspring affected with SLE of Chinese descent $[13,14]$. D16S517 is located within intron 5 of a gene named Olf1/EBF associated zinc finger protein $(\mathrm{OAZ}$, also known as zinc finger protein 423; ZNF423) in 16q12. Genotyping of five SNPs within intron 4 and intron 5 of OAZ reveals preferential transmission of haplotypes containing SNPs and/or the SLEassociated D16S517 allele [14], suggesting OAZ may be a positional candidate gene within the $16 \mathrm{q}$ interval.

Currently there is no evidence indicating OAZ in the pathogenesis of SLE. OAZ is a transcriptional factor that binds to DNA through its zinc fingers, which acts as a bone morphogenetic protein (BMP) induced co-regulator of the Smad1 to Smad4 complex [15]. Through model biology study, OAZ is found to be necessary in BMP-4 induced gene activation [16]. Among the various genes activated via BMP signaling, ID (inhibitor of differentiation or inhibitor of DNA binding) proteins involved in the regulation of cell differentiation and proliferation may be the most important targets [17]. Four ID proteins (ID1 to 4) have been identified in mammals, in which ID3 is required for normal B cell functions [18]. Thus, it is plausible that OAZ may act through these IDs to regulate immune responses.

The presence of antinuclear antibodies (ANA), found in $95 \%$ of the patients, is the most prevalent feature of SLE that may play a pivotal role in the disease pathogenesis. These antibodies bind to a variety of macromolecules, including DNA, RNA and proteins, and some of them, notably anti-dsDNA and anti-Sm, are specific for the disease. Both the B-cell and T-cell compartments exhibit functional abnormalities that could lead to the autoantibody production in SLE [19]. Here we showed that OAZ expression levels were elevated in patients affected with SLE but not RA, correlated with disease activity and associated with positivity for anti-dsDNA and anti-RNA binding protein (anti-RBP) antibodies. In addition, silencing OAZ expression correlated with decreased production of ANA, IL-21, but elevated CCL2. These findings support a role of OAZ in the pathogenesis of SLE.

\section{Materials and methods \\ Patients and controls}

Study protocol was reviewed and approved by the Ethics Committee of the Affiliated Drum Tower Hospital of Nanjing University Medical School where all subjects were recruited, excluding those with a current infection. All patients and healthy volunteers provided written informed consents to participate in the study. Enrollment criteria for SLE patients were 1) fulfillment of the 1997 revised criteria of the American College of Rheumatology [20], and 2) with positive serum ANA (a titer $>1: 100$ dilution) at the study entry. Healthy volunteers were recruited as normal controls with an effort to match age and gender of SLE patients. Rheumatoid arthritis (RA) patients who meet the 1987 American College of Rheumatology classification criteria [21] were recruited as disease controls. In total 40 SLE patients, 30 normal controls and 18 RA patients were enrolled for measuring the gene expressions in peripheral blood cells (Table 1 ).

At the beginning of the study, each SLE patient was assessed for the presence of ANA and IgG antibodies to anti-dsDNA and anti-extractable nuclear antigen using reagents from Euroimmun AG (Lübeck, Germany) and disease activity at the time of blood drawn was assessed by their rheumatologists and verified by two of the authors (RL and BH) using the SLE disease activity index (SLEDAI) [22]. Among the 40 patients having their gene expressions measured in peripheral blood, 38 were treated with steroids (an average dose of $34.6 \pm 2.6 \mathrm{mg}$ per day of methylprednisolone (from $6 \mathrm{mg}$ to $80 \mathrm{mg}$ according to their disease activity)), 18 were taking hydrochloroquine, 5 were on cellcept or cyclosporin and 8 were on non-steroidal antiinflammatory drug at the time of blood draw.

\section{Sample collection and RNA processing}

A 2 to $3 \mathrm{ml}$ sample of blood was collected in BD Vacutainer spray-coated K2EDTA Tubes (BD Biosciences, San Jose, CA, USA) and total RNA from whole cells was extracted immediately using Trizol (Invitrogen, Carlsbad, CA, USA). A 1 to $2 \mu \mathrm{g}$ aliquot of total RNA was reverse transcribed into complementary DNA (cDNA) using Superscript II reverse transcriptase (Invitrogen, USA). All RNA and cDNA samples were stored at $-70^{\circ} \mathrm{C}$ before use.

\section{Gene expression measuring}

Primers were designed using the Primer Express 2.0 Software (Applied Biosystems, Foster City, CA, USA) according to the total mRNA sequences of OAZ 
Table 1 Demographics of SLE patients, normal controls and disease controls*

\begin{tabular}{|c|c|c|c|}
\hline & SLE patients $(n=40)$ & Normal controls $(n=30)$ & Disease controls $(n=18)^{+}$ \\
\hline Age, years & $33.48 \pm 2.11(14$ to 70$)$ & $29.23 \pm 1.13$ (19 to 42$)$ & $38.39 \pm 2.02(18$ to 54$)$ \\
\hline Female gender & $33(82.5 \%)$ & $24(80.0 \%)$ & 17 (94.1\%) \\
\hline Disease duration, years & $5.91 \pm 0.94$ (0.08 to 20$)$ & & \\
\hline SLEDAI score & $7.70 \pm 0.90(1$ to 27$)$ & & \\
\hline \multicolumn{4}{|l|}{ Autoantibodies } \\
\hline Anti-dsDNA & $15(37.5 \%)$ & & \\
\hline Anti-Sm & $19(47.5 \%)$ & & \\
\hline Anti-SSA & $18(45.0 \%)$ & & \\
\hline Anti-SSB & $14(35.0 \%)$ & & \\
\hline Anti-U1RNP & 9 (22.5\%) & & \\
\hline
\end{tabular}

*Values are shown by mean \pm SEM (range) or number (percentage). There were no significant differences between patients with systemic lupus erythematosus (SLE) and normal controls or disease controls in terms of age and gender.

${ }^{+}$Consisted of 18 patients with rheumatoid arthritis. SLEDAI, Systemic Lupus Erythematosus Disease Activity Index.

(NM_015069), ID1 (NM_002165), ID2 (NM_002166), ID3 (NM_002167) and ID4 (NM_001546). Human ribosomal protein, large, P0 (RPLP0) was used as the housekeeping gene to normalize cellular RNA amounts. All the primers were synthesized by Takara Corp (Shanghai, China) and the sequences were shown in Table 2.

Experiments were performed in triplicate for each sample in 96-well plates using SYBR Green I Dye in the Applied Biosystems 7500 real-time PCR system. Reactions were performed in a $20 \mu \mathrm{l}$ reaction volume and cycling times and temperatures were as follows: initial denaturation was carried out for 10 seconds at $95^{\circ} \mathrm{C}$, followed by 45 cycles of denaturation at $95^{\circ} \mathrm{C}$ for 5 seconds and combined primer annealing/extension at $60^{\circ} \mathrm{C}$ for 34 seconds. Data were displayed using SDS software, version 2.0 (Applied Biosystems, USA). The $\Delta C T$ value was determined by subtracting the RPLPO (the house keeping gene) CT value from the target gene CT value. Relative gene expressions were calculated as $2^{-(\Delta \mathrm{CT} \text { each- }}$ $\Delta \mathrm{CT}$ mean) where $\Delta \mathrm{CT}$ each $=\Delta \mathrm{CT}$ value of each sample, $\Delta \mathrm{CT}$ mean $=$ mean $\Delta \mathrm{CT}$ values of normal controls.

\section{RNA Interference}

Accell siRNA was a novel form of short-interfering RNA that was absorbed directly by cells without the use of conventional delivery methods such as transfection reagents or viruses. Four pairs of siRNA sequences targeting OAZ were designed and synthesized by Dharmacon (Accell SMARTpool siRNA A-012907 13-16, Thermo Fisher Scientific, Waltham, MA, USA). SiRNA with a non-targeting sequence was used as a negative control, and siRNA targeting glyceraldehyde-3-phosphate dehydrogenase (GAPDH) was used as a positive control (Table 3).

Blood was drawn from five randomly selected female SLE patients $(40.40 \pm 1.69$ yrs old $)$ and OAZ gene silencing was performed according to the manufacturer's instructions (Dharmacon). Briefly, mononuclear cells were collected by Ficoll-Hypaque discontinuous gradient, resuspended in siRNA buffer, distributed to 96-well plate at $2 \times 10^{5}$ per well, and then divided into OAZ silence group (OAZ sil, added with OAZ siRNA mixture using SMARTpool technique), positive control group (added with GAPDH siRNA), negative control group (Neg ctl, added with non-targeting siRNA) and mock group (only culture medium added). For each sample, 4 to 10 replications in each group were applied. Cells were incubated at $37^{\circ} \mathrm{C}$ with $5 \% \mathrm{CO}_{2}$ for 72 hour and trypan blue exclusion test of cell viability was done by counting 200 cells before and after cell culture. After culturing, supernatants were collected and cells were harvested, RNA was extracted and then reverse transcribed to cDNA. Specific inhibition efficacy of OAZ, ID1-4 and GAPDH was confirmed by qPCR.

Table 2 Primers for real-time PCR

\begin{tabular}{lll}
\hline Gene & Forward & Reverse \\
\hline OAZ & CTG CTC ACA GTG CCC TCA GAA G & ACT GTG CGT GCT GGC TCA TC \\
ID1 & GTA AAC GTG CTG CTC TAC GAC ATG A & AGC TCC AAC TGA AGG TCC CTG A \\
ID2 & TGT CAG CCT GCA TCA CCA GA & CCA CAC AGT GCT TTG CTG TCA \\
ID3 & TCA GCT TAG CCA GGT GGA AAT C & GGC TGT CTG GAT GGG AAG GT \\
ID4 & GAT CCT GCA GCA CGT TAT CGA CT & AAT GCT GTC GCC CTG CTT G \\
RPLP0 & GTT TCA TTG TGG GAG CAG ACA & CAT GGT GTT CTT GCC CAT CA \\
\hline
\end{tabular}

$\mathrm{PCR}$, polymerase chain reaction. 
Table 3 Accell siRNA sequences

\begin{tabular}{lll}
\hline Gene & Sense & Antisense \\
\hline OAZ & GUA AUG AAU AUA AUC & AAC CGA UUA UAU UCA \\
& GGU U & UUA C \\
OAZ & GCA UCA ACC ACG AGU & UUA CAC UCG UGG UUG \\
& GUA A & AUG C \\
OAZ & GGA GGA UGA AUC AAU & GUA AAU UGA UUC AUC \\
& UUA C & CUC C \\
OAZ & CCU UCA UGU AUU AUA & UCA AUA UAA UAC AUG \\
& UUG A & AAG G \\
Nt & UUC UCC GAA CGU GUC & ACG UGA CAC GUU CGG \\
& ACG U & AGA A \\
GAPDH & GUA UGA CAA CAG CCU & CUU GAG GCU GUU GUC \\
& CAA G & AUA C \\
\hline
\end{tabular}

$\mathrm{Nt}$, non-targeting siRNA

\section{Immunoglobulin and antinuclear antibody detection}

Total IgG and IgM levels were measured by commercial ELISA kits (Westang Bio-Tech Co., Shanghai, China). Cultured supernatants were diluted in 1:10 for IgG test and undiluted for IgM test. ANA levels were detected by ELISA and also indirect immunofluorescence according to manufacturer's instruction (Euroimmun, Lübeck, Germany). An ANA value for each sample was calculated by OD sample/OD standard obtained from the ELISA test. As for the immunofluorescence test, undiluted samples were layered on HEp-2 cell spots and incubated for 30 minutes. After washing, fluorescein-labeled antihuman globulin was added to each spot and incubated for another 30 minutes. Slides were then embedded and read under the fluorescent microscope (Olympus; Tokyo, Japan). The criterion for assigning intensity of fluorescence was as follows: $4+$ (very bright green), $3+$ (bright green), $2+$ (green), $1+$ (faint green)

\section{Cytokine and chemokine measurements}

Interferon $\gamma$ (IFN- $\gamma$ ), interleukin 4 (IL-4), IL-10, IL-12, IL-21 and chemokine (C-C motif) ligand 2 (CCL2) levels in supernatants obtained from the previous step were measured by EIA kits ( $R$ \& D Systems, Minneapolis, MN, USA). For each cytokine, samples and diluted standards were added to pre-embedded plate and incubated for two hours at $37^{\circ} \mathrm{C}$. Then biotinylated anti-human detection antibody was added to each well. The plate was incubated for one hour at $37^{\circ} \mathrm{C}$ and developed with the addition of Streptavidin-HRP and tetramethylbenzidine as a substrate. The optical density for each well was documented with a microplate reader (Tecan Sunrise, Männedorf, Switzerland) set to $450 \mathrm{~nm}$ and levels of cytokines and chemokine $(\mathrm{pg} / \mathrm{ml})$ were calculated according to their standard curves.

\section{Statistical analysis}

Results are presented as means \pm SEM. Because gene expressions were extremely altered in certain patients, those levels were transformed to $\log 10$ values for analysis. To observe the changes of gene expressions, cytokine/chemokine levels and ANA values due to OAZ silence, an excitation-inhibition ratio (EIR) for each sample was calculated according to the formula: $\mathrm{EIR}=\frac{\text { Value }_{\text {OAZsil }}}{\text { Value }_{\text {Negctr }}}$. For comparing the results between two groups, Student's t-test was conducted if the variance was normally distributed, whereas the Mann-Whitney $\mathrm{U}$ test was used if the variance was not normally distributed. Correlation between groups was evaluated using the Pearson rank test. Data were analyzed using the Prism 3.0 program (GraphPad, La Jolla, CA, USA), and $P<0.05$ was considered significant.

\section{Results}

\section{OAZ highly expressed in SLE patients and correlated with disease activity}

To explore whether OAZ was differentially expressed in SLE, mRNA levels relative to a house keeping gene were measured by qPCR using peripheral blood cells from 40 SLE patients, 30 matched normal controls and 18 RA patients, and then transformed to $\log 10$ values. As shown in Figure 1a, OAZ gene were highly expressed in peripheral blood samples from SLE patients as compared to those from normal controls $(0.79 \pm 0.13$ vs $0.001 \pm 0.109$, $P<0.0001)$ and RA patients $(0.79 \pm 0.13$ vs $-0.04 \pm 0.22$, $P<0.01$ ), while there was no difference between those from normal controls and RA patients $(P>0.05)$. The expression data of OAZ in SLE patients were compared with varying levels of disease activity as assessed by the SLEDAI score at the time blood was obtained. A positive correlation between OAZ values and SLEDAI scores was observed (Pearson $r=0.72, P<0.0001$ ) (Figure 1b).

\section{OAZ associated with autoantibody production in SLE patients}

Since the production of antinuclear autoantibodies is the most ubiquitous feature in SLE, SLE predisposing factors should impact on ANA production [23]. Within our 40 patients, all had a positive ANA (titers $>1: 100$ ) at the time of blood draw, while 15 had concurrent IgG anti-dsDNA, 19 had anti-Sm, 18 had anti-SSA, 14 had anti-SSB and 9 had anti-U1 RNP. We found OAZ expressions were higher in patients with positive antidsDNA antibodies as well as in those with positive antiSm antibodies (both $P<0.05$, Figure 1c). However, there were no associations between OAZ expression and anti-SSA, SSB or U1RNP antibodies (data not shown).

\section{Diminished ANA production after OAZ silence}

To assess whether OAZ expression might regulate autoantibody production in vitro, mRNA expression in peripheral blood mononuclear cells from SLE patients were 

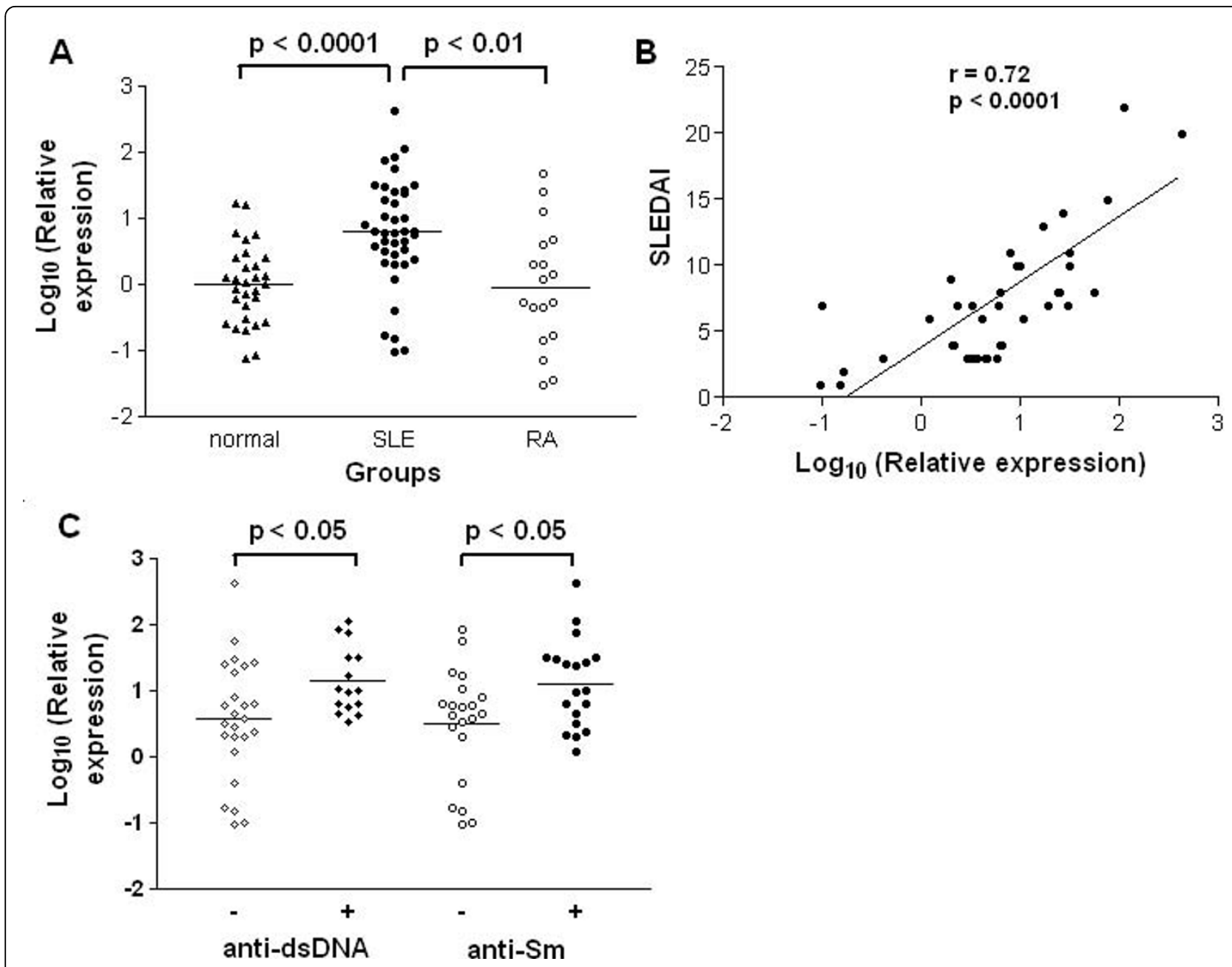

Figure 1 OAZ highly expressed in SLE patients and associated with disease activity as well as anti-dsDNA and anti-Sm antibodies. a. Elevated OAZ expressions in peripheral blood cells from SLE patients. Each symbol represents an individual sample and horizontal lines shows mean values. The log10 values of OAZ expression levels were $0.79 \pm 0.13$ in SLE patients, $0.001 \pm 0.109$ in normal controls and $-0.04 \pm 0.22$ in RA patients. b. OAZ expression correlated with SLE disease activity index (SLEDAI). According to Pearson's correlation test, the log 10 values of OAZ expression levels in peripheral blood cells from 40 SLE patients were significantly correlated with SLEDAI scores $(r=0.72, P<0.0001)$. c. OAZ expression associated with anti-dsDNA and anti-Sm antibodies. Each symbol represents an individual sample and horizontal lines showed mean values. Patients were divided into two groups according to their anti-dsDNA or anti-Sm antibody detection results at the time of blood drawn. Those with positive anti-dsDNA antibody or anti-Sm antibody had a higher expression of OAZ in peripheral blood than those without (both $P<0.05)$.

knocked down by OAZ siRNA, with siRNA targeting GAPDH as a specificity control, or siRNA with a non-targeting sequence as a negative control. The percentages of viable cells were $97.6 \pm 1.5 \%$ before cell culture and 94.7 $\pm 1.3 \%$ after the culture and there were no differences in viability among groups. Compared to those from the negative control group (using non-targeting siRNA), OAZ expressions were significantly decreased only in culture cells treated with siRNA specific for OAZ with a $74.6 \pm 6.4 \%$ reduction of expression level (Figure $2 \mathrm{a}$ ). Mean expression of GAPDH was not inhibited by OAZ siRNA, and was decreased by $84.9 \pm 4.7 \%$ by GAPDH siRNA in the positive control group (Figure $2 \mathrm{~b}$ ).
ANA were present in all studied SLE patients, making ANA the most useful test to measure the change of autoantibodies after OAZ knockdown. Because most SLE patients did not have positive anti-dsDNA antibody and anti-Sm antibody in their serum, we measured ANA in culture supernatants as an alternative. As shown in Figure 2c, ANA value was $2.30 \pm 0.20$ in the negative control group and $0.13 \pm 0.03$ in the OAZ knockdown group measured by ELISA $(P<0.01)$. There was no difference in ANA value between negative control group and GAPDH knockdown group $(P>0.05)$. Consistent with ELISA results, intensity of ANA fluorescence was decreased from 2 to approximately $3+$ in the 


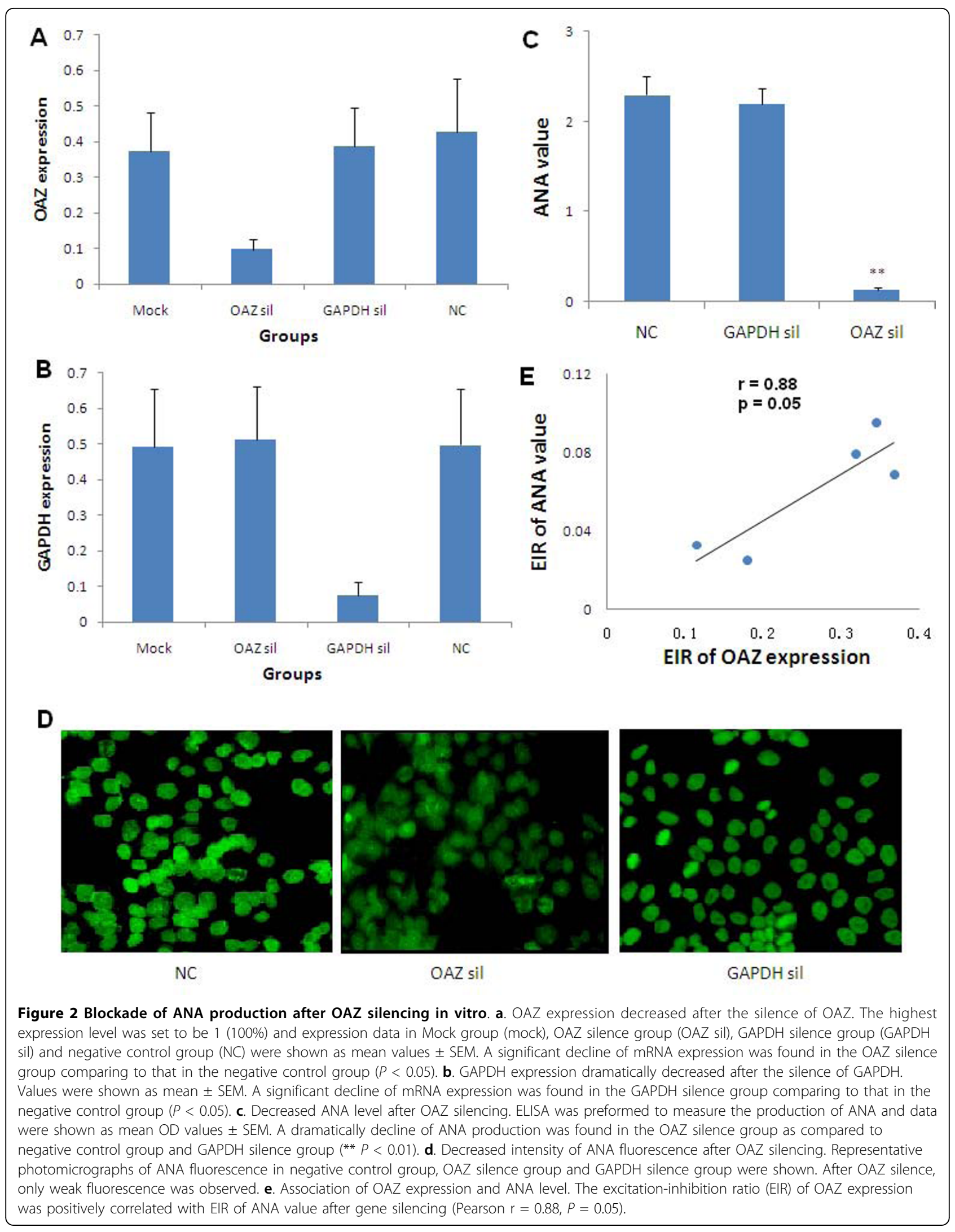


control group to $1+$ in $\mathrm{OAZ}$ silenced group assayed using indirect immunofluorescence (Figure $2 \mathrm{~d}$ ). There was a positive correlation between the EIR of OAZ expression and ANA value $(\mathrm{r}=0.88, P=0.05)$ (Figure $2 \mathrm{e})$, suggesting that $\mathrm{OAZ}$ might play a role in ANA production.

To further confirm a relationship between OAZ expression and antibody production, total IgG and IgM in culture supernatants were measured. IgG levels were significantly decreased in the OAZ knockdown group as compared to those in the negative control group $(26.8 \pm$ $3.7 \mathrm{ug} / \mathrm{ml}$ vs $44.3 \pm 6.4 \mathrm{ug} / \mathrm{ml}, P<0.05$ ), while there was no difference in IgM levels between the two groups $(4.13 \pm 0.56 \mathrm{ug} / \mathrm{ml}$ vs $2.82 \pm 0.36 \mathrm{ug} / \mathrm{ml}, P=0.09)$.

\section{Alteration of cytokine and chemokine levels after OAZ silence}

Production of IgG autoantibodies requires $\mathrm{T}$ cell help, and there are several subpopulations of effector $\mathrm{CD} 4^{+} \mathrm{T}$ lymphocytes (Th cells) based on the cytokines they produced. To assess whether OAZ was linked to the cytokine disturbance that was a prominent phenomenon in SLE, we tested the secretion levels of two Th1 cytokines (IFN- $\gamma$ and IL-12), two Th2 cytokines (IL-4 and IL-10) and one newly discovered Th17-related cytokine (IL-21). As shown in Figure 3a, four of the five cytokines measured were significantly down-regulated after OAZ silencing compared to those in the negative control group. The levels of IFN- $\gamma$, IL-10, IL-12 and IL-21 were $37.8 \pm$ $2.6 \mathrm{pg} / \mathrm{ml}, 175.7 \pm 42.0 \mathrm{pg} / \mathrm{ml}, 160.8 \pm 28.1 \mathrm{pg} / \mathrm{ml}$ and $69.0 \pm 5.5 \mathrm{pg} / \mathrm{ml}$ in the group treated with siRNA to $\mathrm{OAZ}$, while the levels were $21.7 \pm 1.5 \mathrm{pg} / \mathrm{ml}, 52.4 \pm 8.9$ $\mathrm{pg} / \mathrm{ml}, 30.0 \pm 9.3 \mathrm{pg} / \mathrm{ml}$ and $28.1 \pm 3.6 \mathrm{pg} / \mathrm{ml}$ in the negative control group $(P<0.01, P<0.01, P<0.05$ and $P<0.01$ respectively). There was no difference in IL-4 level between the two groups. CCL2, a chemokine that has been implicated as a biomarker for lupus nephritis [24], was significantly increased in the OAZ silenced group compared to those in the negative control group $(298.3 \pm 65.3$ vs $531.5 \pm 46.5, P<0.05)$ (Figure $3 \mathrm{a}$ ).

To identify the relationship between OAZ expression and specific cytokines and/or chemokine, EIR was calculated as described before. There was a positive trend of correlation between the EIR of OAZ expression and the EIR of IL-21 level $(\mathrm{r}=0.83, P=0.08$, Figure $3 \mathrm{~b})$, suggesting the more decreased levels of OAZ, the lower levels of IL-21. The EIR of OAZ expression was negatively correlated with the EIR of CCL2 level $(r=-0.89, P$ $<0.05$, Figure $3 \mathrm{c}$ ), indicating a strong negative correlation between OAZ transcripts and the secreted levels of CCL2 in cultures of peripheral blood cells from SLE patients.

Strikingly, there was a perfect positive correlation between EIR of IL-21 levels and EIR of ANA value, and a negative correlation between EIR of CCL2 levels and EIR of ANA value $(\mathrm{r}=0.99$ and $\mathrm{r}=-0.98$, both $P<$ 0.01) (Figure 3d, e), providing evidence that these two factors might be important in the production of ANA.

\section{ID3 gene participated in OAZ pathway in SLE}

Since ID expression might be regulated by OAZ, expressions of all the four ID genes were measured after OAZ knockdown. ID1 to 3, but not ID4, were significantly down-regulated with an average decline of $68.7 \%, 70.2 \%$ and $67.7 \%$, respectively, as compared to those of negative control (Figure 4a), supporting that expression of these genes in SLE patients might be regulated by the pathway involving OAZ.

Among the four IDs, ID3 that had putative immunofunctions [25] was selected as a representative for in vivo studies. To assess whether ID3 expressions were related to the disease status, qPCR was applied using peripheral blood cells from 40 SLE patients and 20 normal controls. Our data showed that ID3 was highly expressed in SLE patients compared to that in normal controls $(0.75 \pm 0.09$ vs $0 \pm 0.11, P<0.0001)$ and there was a positive correlation between ID3 expression level and SLEDAI score $(\mathrm{r}=0.76, P<0.0001)$ (Figure $4 \mathrm{~b}, \mathrm{c}$ ). Meanwhile, a correlation between OAZ and ID3 expression levels was observed $(\mathrm{r}=0.55, P=0.0002)$. ID3 expressions were also elevated in those with positive anti-dsDNA or anti-Sm antibodies (Figure 4d), indicating that ID3 could play a role in the regulation of OAZ driven ANA production.

Abnormal activation of the type I interferon pathway presents in most SLE patients particularly in those expressing anti-RBP antibodies [26]. To address whether siRNA for OAZ might non-specifically inactivate the type I interferon pathway, the expression level of LY6E, a type I interferon inducible gene [27], was measured after OAZ knockdown. No significant alteration of LY6E expression was observed among groups treated with non-targeting GAPDH- or OAZ- targeting SiRNA (data not shown).

\section{Discussion}

To our knowledge, this is the first report to implicate a functional role of OAZ, a novel positional lupus candidate gene, in the pathogenesis of SLE. Dysregulation of OAZ expression modulated the ANA production of SLE patients. Our studies showed that OAZ mRNA levels in peripheral blood cells were elevated in SLE patients as compared to those in either normal or disease controls (RA patients). Transcript levels of OAZ were highly correlated with disease activity $(\mathrm{r}=0.72, P<0.0001)$ as well as associated with the presence of autoantibodies to dsDNA or Sm (Figure 1). OAZ expressions were negatively correlated with methylprednisolone doses (data 


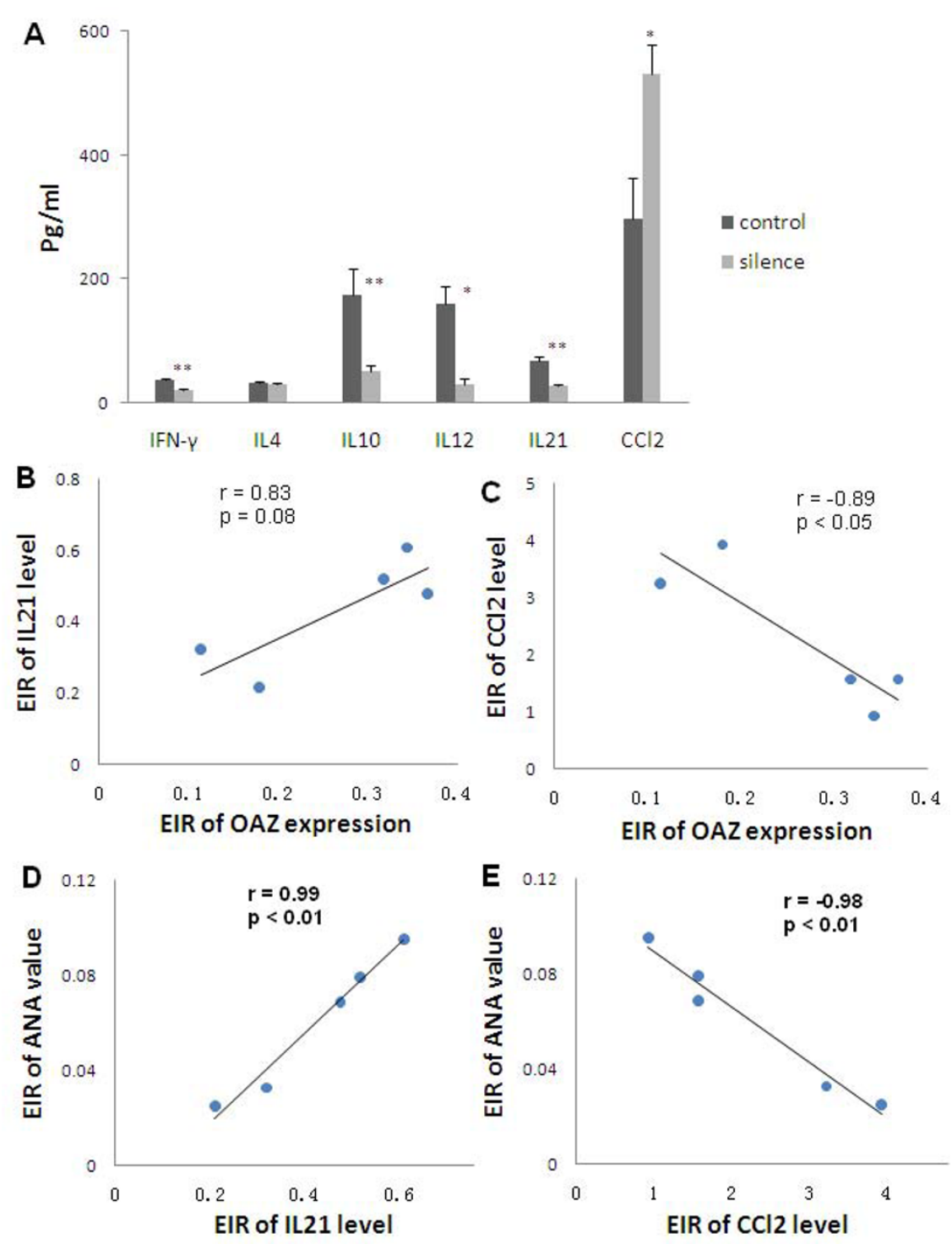

Figure 3 Alteration of cytokine and chemokine levels after OAZ silencing. a. IFN- $\gamma$, IL-10, IL-12 and IL-21 levels were significantly decreased in culture supernatants of OAZ silence group (silence) as compared to those of negative control group (control), while IL-4 levels remained unchanged and CCL2 levels were increased in culture supernatants of silence group. Values were shown as means \pm SEM (** $P<0.01, * P<$ 0.05). b, $\mathbf{c}$. The relationship between OAZ expression and IL-21 as well as CCL2. There was a tendency for the excitation-inhibition ratio (EIR) of OAZ expression to be positively correlated with EIR of IL-21 level (Pearson $r=0.83, P=0.08$ ), while the EIR of OAZ expression was negatively correlated with EIR of CCL2 level (Pearson $r=-0.89, P<0.05$ ). d, e. Association of IL-21, CCL2 and ANA level. EIR of IL-21 level was positively correlated with EIR of ANA value (Pearson $r=0.99, P<0.01$ ), while EIR of the CCL2 level was negatively correlated with EIR of ANA value (Pearson $r=-0.98, P<0.01)$.

not shown), implying that there should be an even greater elevation of OAZ expression in those patients with high SLEDAI scores because they were treated with high dose of steroids. When OAZ expression in peripheral blood mononuclear cells was silenced in vitro, mRNA levels of OAZ and ID1-3 were concomitantly decreased, together with a reduction of IFN- $\gamma$, IL-10, IL12 and IL-21 levels, an elevation of CCL2 level, and decreased levels of total IgG and ANA (Figures 2 and 3).
The extent of decreased ANA level was correlated with the inhibition of OAZ expression, the reduction of IL-21 level and the elevation of CCL2 level. Interestingly, ID3, a gene that was down-regulated after OAZ silence, was also highly expressed in SLE patients and associated with disease activity as well as the presence of anti-dsDNA or anti-Sm autoantibodies (Figure 4).

OAZ is present in cell nucleus and acts as a DNAbinding partner of BMP-Activated Smads [15]. 


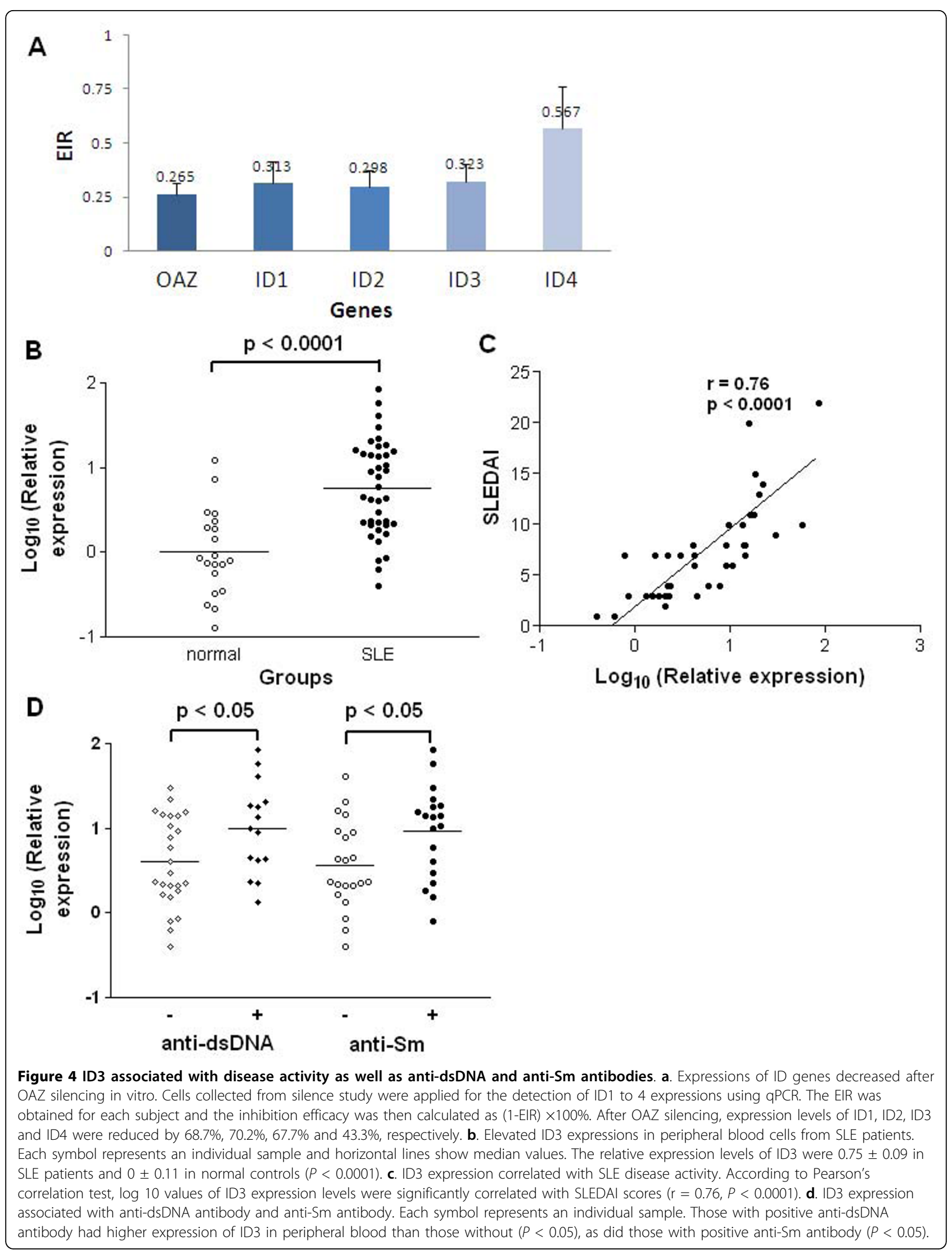


According to our results, mRNA expression of OAZ is very low in peripheral blood cells (approximately $0.002 \%$ of the expression level of the house-keeping gene), making it difficult to be detected in the protein level. To ensure a specific amplification of this gene, primers have been blasted after the designation [28]. Besides, only OAZ but not EHZF, an OAZ homology gene that highly expressed in primitive human hematopoietic cells [29], showed differential expression in bone marrow cells between SLE patients and healthy donors in our preliminary study. The Accell siRNA delivery method, which has recently been widely used to silence genes in many cell types including those difficult-to-transfect immune cells [30-32], provides us a highly efficient way to study genes with low expressions but important functions.

In this paper, OAZ was found to be associated with autoantibody production in vivo and in vitro, suggesting that highly expressed OAZ in SLE patients might promote differentiation of B lymphocytes to antibodysecreting cells. Support evidence for this hypothesis includes that 1) overexpression of OAZ in the neuroblastoma cells leads to enhanced differentiation [33], and 2) suppression of OAZ expression reduces cell growth and contributes to the blast crisis stage in chronic myelogenous leukemia mouse model as the result of the differentiation block [34]. However, it is not clear how OAZ mediates its role in cell differentiation at present. As one of the largest members of the Kruppel-like zinc finger protein family, OAZ provides specificity in BMP signaling while ID genes are thought to be important targets of BMP signaling [15,35]. Based on the study of osteoblast differentiation of mesenchymal stem cells, both RNA interference-mediated knockdown and constitutive overexpression of Id genes are associated with diminished cell differentiation, implicating that Id proteins could play a dual role in BMPmediated differentiation [36].

Among the four ID proteins, ID3 is known to have important functions in the immune system, although its specific role is yet to be delineated. Young ID3-deficient mice (6 to 12 weeks old) have defective immune responses displaying as a $\mathrm{B}$-cell defect in the proliferation and attenuated antibody production [25]. Meanwhile, the production of IgG2a (a Th1 response immunoglobulin) is impaired along with a decreased expression of IFN- $\gamma$ when stimulated with anti-CD3 in these mice. When E2A, an ID3 antagonist gene, was knocked down, mice frequently developed ANA and proteinuria at age eight months or older [37]. Thus a sustained high expression of ID3 might trigger abnormal immunity in SLE patients, facilitating the production of autoantibodies. To support this notion, our current data have shown a good correlation between ID3 and OAZ expressions and an association of ID3 expression with both anti-dsDNA and
anti-Sm antibodies. Besides ID pathway, OAZ has been shown to be a component of retinoic acid signaling, and plays a key role in retinoic acid-induced differentiation through the regulation of retinoic acid receptors [33]. In addition, OAZ may act as a corepressor of EBF (early B cell factor) [38], and thus inhibit the transcription of a lot B lineage genes including Pax-5 [39] and consequently affect plasma cell differentiation [40,41]. It is reasonable that these pathways could also be helpful in OAZ induced $\mathrm{B}$ lymphocyte differentiation and antibody production in SLE patients.

Studies have implicated that cytokines and chemokines are involved in the differentiation of B lymphocytes into plasma cells [42,43]. The decreased level of Th1cytokines (IFN- $\gamma$ and IL-12) in our case after OAZ silence is similar to that found in ID3-deficient mice [25], supporting a role of OAZ-ID3 pathway in this process. IL-10 is a well-known mediator of human B cell differentiation that has a powerful effect on the stimulation of immunoglobulin secretion by B cells in SLE [44]. IL-21 has a critical role in terminal B cell differentiation to plasma cells and has recently been identified as an important component in the development of autoimmune disease [45-47]. Our in vitro results suggested that OAZ could regulate IL-10 and IL-21 level in SLE. The near perfect correlation between the extent of IL-21 and ANA suppression by OAZ knockdown suggested that this cytokine could be a key mediator for OAZ induced $B$ cell differentiation and ANA production. In addition to these cytokines, a chemokine, CCL2, has been shown to suppress plasma cell immunoglobulin production via STAT3 inactivation and PAX5 induction [48]. Of note, the expression of CCL2 is effectively regulated by BMP members [49]. In our experiment, CCL2 might work as a negative regulator of plasma cell differentiation when upregulated via OAZ silence.

\section{Conclusions}

OAZ has been previously considered as a positional candidate gene for susceptibility to SLE. Our data provide evidence for functional relevance of OAZ in SLE in the production of antinuclear antibody, a hallmark of SLE, along with the alterations of several cytokines and chemokine especially those involved in the regulation of plasma cell function. As a complex network, BMPSmad-IDs, retinoic acid receptor and Olf-1/EBF pathways could participate in OAZ-driven ANA production. Further studies are required for elucidating the molecular mechanisms of the OAZ gene in the development of autoimmune diseases.

\section{Abbreviations}

ANA: antinuclear antibodies; Anti-RBP: anti-RNA binding protein; CCL2: chemokine (C-C motif) ligand 2; CDNA: complementary DNA; EBF: early B cell 
factor; EIR: excitation-inhibition ratio; GAPDH: glyceraldehyde-3-phosphate dehydrogenase; ID: inhibitor of differentiation/inhibitor of DNA binding; IFN: interferon; Ig: immunoglobulin; IL: interleukin; LY6E: lymphocyte antigen 6 complex, locus E; OAZ: olf1/EBF associated zinc finger protein; PBLs: peripheral blood cells; PBMCs: peripheral blood mononuclear cells; qPCR: quantitative real-time PCR; RA: rheumatoid arthritis; RPLPO: human ribosomal protein, large, PO; SLE: systemic lupus erythematosus; SLEDAI: SLE disease activity index.

\section{Acknowledgements}

We thank all the patients and healthy volunteers participating in this study. This work was supported by Jiangsu Natural Science Foundation Grant (BK2004009), Chinese National Natural Science Fund (30972735) and Jiangsu Province 135 Talented Grant (2007002). BPT was supported by NIH RO1 43824.

\section{Author details}

'Department of Rheumatology, Nanjing Drum Tower Hospital, the Affiliated Hospital of Nanjing University Medical School, 321 Zhongshan Road, Nanjing, 210008, PR China. ²Division of Rheumatology, David Geffen School of Medicine at UCLA, 1000 Veteran Avenue, Los Angeles, CA 90095-1670, USA.

\section{Authors' contributions}

XF contributed to the design of the study, served as the study coordinator and drafted the manuscript. RL carried out the siRNA studies and cytokine/ chemokine/ANA measurements. $\mathrm{JH}$ participated in the gene expression studies. $\mathrm{HZ}$ participated in data analysis. $\mathrm{LZ}$ and $\mathrm{BH}$ contributed to patient recruitment and management and to data collection. BPT was involved in critically revising the manuscript. LS participated in the design of the study and gave final approval of the version to be published. All authors read and approved the final manuscript.

\section{Competing interests}

The authors declare that they have no competing interests.

Received: 22 November 2009 Revised: 12 December 2009 Accepted: 1 April 2010 Published: 1 April 2010

\section{References}

1. Forabosco P, Gorman JD, Cleveland C, Kelly JA, Fisher SA, Ortmann WA, Johansson C, Johanneson B, Moser KL, Gaffney PM, Tsao BP, Cantor RM, Alarcon-Riquelme ME, Behrens TW, Harley JB, Lewis CM, Criswell LA: Metaanalysis of genome-wide linkage studies of systemic lupus erythematosus. Genes Immun 2006, 7:609-614.

2. Nath SK, Namjou B, Hutchings D, Garriott CP, Pongratz C, Guthridge J, James JA: Systemic lupus erythematosus (SLE) and chromosome 16: confirmation of linkage to $16 q 12-13$ and evidence for genetic heterogeneity. Eur J Hum Genet 2004, 12:668-672.

3. Tsao BP, Cantor RM, Grossman JM, Kim SK, Strong N, Lau CS, Chen CJ, Shen N, Ginzler EM, Goldstein R, Kalunian KC, Arnett FC, Wallace DJ, Hahn BH: Linkage and interaction of loci on $1 \mathrm{q} 23$ and $16 q 12$ may contribute to susceptibility to systemic lupus erythematosus. Arthritis Rheum 2002, 46:2928-2936.

4. Cantor RM, Yuan J, Napier S, Kono N, Grossman JM, Hahn BH, Tsao BP: Systemic lupus erythematosus genome scan: support for linkage at $1 q 23,2 q 33,16 q 12-13$, and 17q21-23 and novel evidence at 3p24, 10q23-24, 13q32, and 18q22-23. Arthritis Rheum 2004, 50:3203-3210.

5. Gaffney PM, Ortmann WA, Selby SA, Shark KB, Ockenden TC, Rohlf KE, Walgrave NL, Boyum WP, Malmgren ML, Miller ME, Kearns GM, Messner RP, King RA, Rich SS, Behrens TW: Genome screening in human systemic lupus erythematosus: results from a second Minnesota cohort and combined analyses of 187 sib-pair families. Am J Hum Genet 2000, 66:547-556.

6. Gaffney PM, Langefeld CD, Graham RR, Ortmann WA, Williams AH, Rodine PR, Moser KL, Behrens TW: Fine-mapping chromosome 20 in 230 systemic lupus erythematosus sib pair and multiplex families: evidence for genetic epistasis with chromosome 16q12. Am J Hum Genet 2006, 78:747-758.

7. Gaffney PM, Kearns GM, Shark KB, Ortmann WA, Selby SA, Malmgren ML, Rohlf KE, Ockenden TC, Messner RP, King RA, Rich SS, Behrens TW: A genome-wide search for susceptibility genes in human systemic lupus erythematosus sib-pair families. Proc Natl Acad Sci USA 1998, 95:14875-14879.

8. Gillett CD, Langefeld CD, Williams AH, Ortmann WA, Graham RR, Rodine PR, Selby SA, Gaffney PM, Behrens TW, Moser KL: Fine mapping chromosome $16 q 12$ in a collection of 231 systemic lupus erythematosus sibpair and multiplex families. Genes Immun 2005, 6:19-23.

9. Harley JB, Alarcon-Riquelme ME, Criswell LA, Jacob CO, Kimberly RP, Moser KL, Tsao BP, Vyse TJ, Langefeld CD, Nath SK, Guthridge JM, Cobb BL, Mirel DB, Marion MC, Williams AH, Divers J, Wang W, Frank SG, Namjou B, Gabriel SB, Lee AT, Gregersen PK, Behrens TW, Taylor KE, Fernando M, Zidovetzki R, Gaffney PM, Edberg JC, Rioux JD, Ojwang JO, et al: Genomewide association scan in women with systemic lupus erythematosus identifies susceptibility variants in ITGAM, PXK, KIAA1542 and other loci. Nat Genet 2008, 40:204-210.

10. Hom G, Graham RR, Modrek B, Taylor KE, Ortmann W, Garnier S, Lee AT, Chung SA, Ferreira RC, Pant PV, Ballinger DG, Kosoy R, Demirci FY, Kamboh Ml, Kao AH, Tian C, Gunnarsson I, Bengtsson AA, RantapaaDahlqvist S, Petri M, Manzi S, Seldin MF, Ronnblom L, Syvanen AC, Criswell LA, Gregersen PK, Behrens TW: Association of systemic lupus erythematosus with C8orf13-BLK and ITGAM-ITGAX. N Engl J Med 2008, 358:900-909

11. Nath SK, Han S, Kim-Howard X, Kelly JA, Viswanathan P, Gilkeson GS, Chen W, Zhu C, McEver RP, Kimberly RP, Alarcon-Riquelme ME, Vyse TJ, Li QZ, Wakeland EK, Merrill JT, James JA, Kaufman KM, Guthridge JM, Harley JB: A nonsynonymous functional variant in integrin-alpha(M) (encoded by ITGAM) is associated with systemic lupus erythematosus. Nat Genet 2008, 40:152-154.

12. Nath SK, Quintero-Del-Rio Al, Kilpatrick J, Feo L, Ballesteros M, Harley JB: Linkage at $12 q 24$ with systemic lupus erythematosus (SLE) is established and confirmed in Hispanic and European American families. Am J Hum Genet 2004, 74:73-82.

13. Feng XB, Shen N, Chen SL, Qian J, Wu H, Bao CD, Wang Y: [Susceptibility gene of systemic lupus erythematosus in 16q12 in Chinese cohort]. Zhonghua Yi Xue Yi Chuan Xue Za Zhi 2003, 20:27-30.

14. Shen $N$, Feng $X B$, Qian J, Wang $Y$, Hahn BH, Tsao BP: Identification of a novel candidate gene within the putative SLE susceptibility locus at $16 q 12$ in a Chinese cohort. Arthritis Rheum 2003, 48:S257.

15. Hata A, Seoane J, Lagna G, Montalvo E, Hemmati-Brivanlou A, Massague J: OAZ uses distinct DNA- and protein-binding zinc fingers in separate BMP-Smad and Olf signaling pathways. Cell 2000, 100:229-240.

16. Shim S, Bae N, Han JK: Bone morphogenetic protein-4-induced activation of Xretpos is mediated by Smads and Olf-1/EBF associated zinc finger (OAZ). Nucleic Acids Res 2002, 30:3107-3117.

17. Miyazono K, Maeda S, Imamura T: BMP receptor signaling: transcriptional targets, regulation of signals, and signaling cross-talk. Cytokine Growth Factor Rev 2005, 16:251-263.

18. Sugai $M$, Gonda $H$, Nambu $Y$, Yokota $Y$, Shimizu A: Role of Id proteins in B lymphocyte activation: new insights from knockout mouse studies. $J \mathrm{Mol}$ Med 2004, 82:592-599.

19. Ardoin SP, Pisetsky DS: Developments in the scientific understanding of lupus. Arthritis Res Ther 2008, 10:218.

20. Hochberg MC: Updating the American College of Rheumatology revised criteria for the classification of systemic lupus erythematosus. Arthritis Rheum 1997, 40:1725.

21. Arnett FC, Edworthy SM, Bloch DA, McShane DJ, Fries JF, Cooper NS, Healey LA, Kaplan SR, Liang MH, Luthra HS, et al: The American Rheumatism Association 1987 revised criteria for the classification of rheumatoid arthritis. Arthritis Rheum 1988, 31:315-324.

22. Bombardier C, Gladman DD, Urowitz MB, Caron D, Chang CH: Derivation of the SLEDAl. A disease activity index for lupus patients. The Committee on Prognosis Studies in SLE. Arthritis Rheum 1992, 35:630-640.

23. Sawalha $A H$, Harley JB: Antinuclear autoantibodies in systemic lupus erythematosus. Curr Opin Rheumatol 2004, 16:534-540.

24. Chan RW, Lai FM, Li EK, Tam LS, Wong TY, Szeto CY, Li PK, Szeto CC Expression of chemokine and fibrosing factor messenger RNA in the urinary sediment of patients with lupus nephritis. Arthritis Rheum 2004, 50:2882-2890.

25. Pan L, Sato S, Frederick JP, Sun XH, Zhuang Y: Impaired immune responses and B-cell proliferation in mice lacking the Id3 gene. $\mathrm{Mol}$ Cell Biol 1999, 19:5969-5980. 
26. Hua J, Kirou K, Lee C, Crow MK: Functional assay of type I interferon in systemic lupus erythematosus plasma and association with anti-RNA binding protein autoantibodies. Arthritis Rheum 2006, 54:1906-1916.

27. Feng $X, W u$ H, Grossman JM, Hanvivadhanakul P, FitzGerald JD, Park GS, Dong X, Chen W, Kim MH, Weng HH, Furst DE, Gorn A, McMahon M, Taylor M, Brahn E, Hahn BH, Tsao BP: Association of increased interferoninducible gene expression with disease activity and lupus nephritis in patients with systemic lupus erythematosus. Arthritis Rheum 2006, 54:2951-2962.

28. BLAST: Basic Local Alignment Search Tool. [http://blast.ncbi.nlm.nih.gov/].

29. Bond HM, Mesuraca M, Carbone E, Bonelli P, Agosti V, Amodio N, De Rosa G, Di Nicola M, Gianni AM, Moore MA, Hata A, Grieco M, Morrone G, Venuta S: Early hematopoietic zinc finger protein (EHZF), the human homolog to mouse Evi3, is highly expressed in primitive human hematopoietic cells. Blood 2004, 103:2062-2070.

30. Zhong Z, llieva H, Hallagan L, Bell R, Singh I, Paquette N, Thiyagarajan M, Deane R, Fernandez JA, Lane S, Zlokovic AB, Liu T, Griffin JH, Chow N, Castellino FJ, Stojanovic K, Cleveland DW, Zlokovic BV: Activated protein C therapy slows ALS-like disease in mice by transcriptionally inhibiting SOD1 in motor neurons and microglia cells. J Clin Invest 2009, 119:3437-3449.

31. Mir F, Le Breton GC: A novel nuclear signaling pathway for thromboxane $A 2$ receptors in oligodendrocytes: evidence for signaling compartmentalization during differentiation. Mol Cell Biol 2008, 28:6329-6341.

32. Mookherjee N, Lippert DN, Hamill P, Falsafi R, Nijnik A, Kindrachuk J, Pistolic J, Gardy J, Miri P, Naseer M, Foster LJ, Hancock RE: Intracellular receptor for human host defense peptide LL-37 in monocytes. J Immunol 2009, 183:2688-2696.

33. Huang S, Laoukili J, Epping MT, Koster J, Holzel M, Westerman BA, Nijkamp W, Hata A, Asgharzadeh S, Seeger RC, Versteeg R, Beijersbergen RL, Bernards R: ZNF423 is critically required for retinoic acid-induced differentiation and is a marker of neuroblastoma outcome. Cancer Cell 2009, 15:328-340.

34. Miyazaki K, Yamasaki N, Oda H, Kuwata T, Kanno Y, Miyazaki M, Komeno Y, Kitaura J, Honda Z, Warming S, Jenkins NA, Copeland NG, Kitamura T, Nakamura T, Honda H: Enhanced expression of p210BCR/ABL and aberrant expression of Zfp423/ZNF423 induce blast crisis of chronic myelogenous leukemia. Blood 2009, 113:4702-4710.

35. Miyazono K, Miyazawa K: Id: a target of BMP signaling. Sci STKE 2002, 2002:pe40.

36. Peng Y, Kang Q, Luo Q, Jiang W, Si W, Liu BA, Luu HH, Park JK, Li X, Luo J, Montag AG, Haydon RC, He TC: Inhibitor of DNA binding/differentiation helix-loop-helix proteins mediate bone morphogenetic protein-induced osteoblast differentiation of mesenchymal stem cells. J Biol Chem 2004, 279:32941-32949.

37. Pan L, Bradney C, Zheng B, Zhuang Y: Altered T-dependent antigen responses and development of autoimmune symptoms in mice lacking E2A in T lymphocytes. Immunology 2004, 111:147-154.

38. Tsai RY, Reed RR: Cloning and functional characterization of Roaz, a zinc finger protein that interacts with $\mathrm{O} / \mathrm{E}-1$ to regulate gene expression: implications for olfactory neuronal development. J Neurosci 1997, 17:4159-4169.

39. Singh $\mathrm{H}$, Medina $\mathrm{KL}$, Pongubala JM: Contingent gene regulatory networks and B cell fate specification. Proc Natl Acad Sci USA 2005, 102:4949-4953.

40. Nera KP, Kohonen P, Narvi E, Peippo A, Mustonen L, Terho P, Koskela K, Buerstedde JM, Lassila O: Loss of Pax5 promotes plasma cell differentiation. Immunity 2006, 24:283-293.

41. Delogu A, Schebesta A, Sun Q, Aschenbrenner K, Perlot T, Busslinger M: Gene repression by Pax5 in B cells is essential for blood cell homeostasis and is reversed in plasma cells. Immunity 2006, 24:269-281.

42. Bryant VL, Ma CS, Avery DT, Li Y, Good KL, Corcoran LM, de Waal MR, Tangye SG: Cytokine-mediated regulation of human B cell differentiation into lg-secreting cells: predominant role of IL-21 produced by CXCR5+ T follicular helper cells. J Immunol 2007, 179:8180-8190.

43. Muehlinghaus G, Cigliano L, Huehn S, Peddinghaus A, Leyendeckers $H$, Hauser AE, Hiepe F, Radbruch A, Arce S, Manz RA: Regulation of CXCR3 and CXCR4 expression during terminal differentiation of memory $B$ cells into plasma cells. Blood 2005, 105:3965-3971.

44. Llorente L, Zou W, Levy Y, Richaud-Patin Y, Wijdenes J, Alcocer-Varela J, Morel-Fourrier B, Brouet JC, Alarcon-Segovia D, Galanaud P, Emilie D: Role of interleukin 10 in the B lymphocyte hyperactivity and autoantibody production of human systemic lupus erythematosus. J Exp Med 1995, 181:839-844.

45. Herber D, Brown TP, Liang S, Young DA, Collins M, DunussiJoannopoulos K: IL-21 has a pathogenic role in a lupus-prone mouse model and its blockade with IL-21R. Fc reduces disease progression. J Immunol 2007, 178:3822-3830.

46. Leonard WJ, Zeng R, Spolski R: Interleukin 21: a cytokine/cytokine receptor system that has come of age. J Leukoc Biol 2008, 84:348-356.

47. Ozaki K, Spolski R, Ettinger R, Kim HP, Wang G, Qi CF, Hwu P, Shaffer DJ, Akilesh S, Roopenian DC, Morse HC III, Lipsky PE, Leonard WJ: Regulation of $B$ cell differentiation and plasma cell generation by IL-21, a novel inducer of Blimp-1 and Bcl-6. J Immunol 2004, 173:5361-5371.

48. Rafei M, Hsieh J, Fortier S, Li M, Yuan S, Birman E, Forner K, Boivin MN, Doody K, Tremblay M, Annabi B, Galipeau J: Mesenchymal stromal cellderived CCL2 suppresses plasma cell immunoglobulin production via STAT3 inactivation and PAX5 induction. Blood 2008, 112:4991-4998.

49. Lee MJ, Yang CW, Jin DC, Chang YS, Bang BK, Kim YS: Bone morphogenetic protein-7 inhibits constitutive and interleukin-1 betainduced monocyte chemoattractant protein-1 expression in human mesangial cells: role for JNK/AP-1 pathway. J Immunol 2003, 170:2557-2563.

\section{doi:10.1186/ar2972}

Cite this article as: Feng et al:: Olf1/EBF associated zinc finger protein interfered with antinuclear antibody production in patients with systemic lupus erythematosus. Arthritis Research \& Therapy 2010 12:R59.

\section{Submit your next manuscript to BioMed Central and take full advantage of:}

- Convenient online submission

- Thorough peer review

- No space constraints or color figure charges

- Immediate publication on acceptance

- Inclusion in PubMed, CAS, Scopus and Google Scholar

- Research which is freely available for redistribution

Submit your manuscript at www.biomedcentral.com/submit
C Biomed Central 